\title{
UMA EXPERIÊNCIA DE "DESSILENCIAMENTO" COM O CINEMÁTICA- CINEMA E DEBATE NA MATEMÁTICA (UFJF)
}

\section{AN EXPERIENCE OF "UNSILENCING" WITH THE KINEMATICS-CINEMA AND DISCUSSION IN MATHEMATICS (UFJF)}

\author{
Marco Aurélio Kistemann Júnior ${ }^{1}$ \\ Camila Dias de Sousa ${ }^{2}$ \\ Luiza Harab da Silva Rosa ${ }^{3}$
}

\begin{abstract}
Resumo: Neste relato buscamos apresentar uma experiência realizada durante um projeto denominado Cinemática-Cinema e Debate. O objetivo central do relato é descrever como ocorreu a experiência. O objetivo do projeto foi de promover o que denominamos de "dessilenciamento", ou seja, promover a argumentação dos participantes, professores e estudantes, acerca de temas apresentados em sessões fílmicas com temáticas relativas às práticas escolares docentes. $\mathrm{O}$ projeto, que optou por utilizar uma abordagem qualitativa de pesquisa, contou com a participação de dois pesquisadores, um orientado e uma bolsista que organizavam as sessões para que os debates pudessem ocorrer. Nossas leituras e fundamentações teóricas ao longo da experiência se basearam em investigações de Coelho e Viana (2013), Viana (2009; 2010; 2011) e Viana, Rosa e Orey (2011) e auxiliaram a estruturar as sessões em busca do desenvolvimento de criticidade e "dessilenciamento". Os principais resultados foram proporcionar espaços para debates, a partir de filmes que envolviam o cotidiano de professores, envolver a comunidade acadêmica para exercitar outros olhares e dar vozes aos estudantes por meio de suas argumentações.
\end{abstract}

Palavras-chave: "Dessilenciamento"; Cinema; Argumentação.

\begin{abstract}
In this report we seek to present an experiment carried out during a project called KinematicsCinema and Debate. The main objective of the report is to describe how the experience occurred. The objective of the project was to promote what we call "unsilencing", that is, promoting arguments of the participants, teachers and students, about topics presented in movie themed sessions on school teachers practices. The project, which opted to use a qualitative approach to research, with the participation of two researchers, a targeted and a scholar who organized the sessions so that the discussions could occur. Our readings and theoretical arguments along the experience was based on investigations of Coelho and Viana (2013), Viana (2009; 2010; 2011) and Viana, Rosa and Orey (2011) and helped to structure the sessions in search of criticality and "unsilencing". The main results were providing spaces for debate, from films involving the teachers daily, involve the academic community to exercise other perspectives and give voices to students through its arguments.
\end{abstract}

Keywords: "Unsilencing"; Cinema; Argumentation.

\section{Introdução}

Este artigo apresenta uma experiência realizada durante um projeto denominado

\footnotetext{
1 Doutor em Educação Matemática (UNESP-RIO CLARO-SP). Pesquisador do Departamento de Matemática (UFJF). Líder do Grupo Pesquisa de Ponta (UFJF). E-mail: marco.kistemann@ufjf.edu.br

2 Licencianda em Matemática (UFJF). Membro do Grupo Pesquisa de Ponta (UFJF). E-mail: pesquisadepontaufjf@gmail.com

${ }^{3}$ Mestre em Educação Matemática (UFJF). Professora da Rede Pública e Particular do Estado do Rio de Janeiro. Membro do Grupo Pesquisa de Ponta (UFJF). E-mail: pesquisadepontaufjf@ gmail.com
} 
"Cinemática - Cinema e Debate" realizado no Instituto de Ciências Exatas na Universidade Federal de Juiz de Fora (UFJF) em 2016 e 2017.

O objetivo do artigoé apresentar uma experiência realizada num instituto de Ciências Exatas com a utilização de sessões de cinema denominado de Cinemática-Cinema e Debate nas Ciências Exatas. Nestas sessões, divulgadas para todos os docentes e discentes desse instituto, e também em canais diversos na UFJF, buscou-se exibir um filme pedagógico que tratasse da atuação de um professor e seu cotidiano numa instituição escolar. Com a exibição ambicionou-se convidar os participantes, docentes e discentes a formularem suas argumentações em torno dos temas tratados no filme exibido, ou seja, exercitarem a sua argumentação, ou seja, "dessilenciar-se".

Inicialmente, esclarecemos que o termo "dessilenciamento ou a arte de dessilenciar-se", constitui-se como a ação de verbalizar, oralmente e por meio de produções escritas, o que se vê, ou que se sente ou o que se recordar a partir de imagens, sons, ideias, ou seja, o "dessilenciamento" busca promover a argumentação dos participantes, professores e estudantes, acerca de temas apresentados em sessões fílmicas com temáticas relativas às práticas escolares docentes, no caso do presente projeto desenvolvido.

A área de Ciências Exatas é denominada como a área das "Ciências Duras". Esse termo é usado de forma informal para designar uma área que ainda tem disciplinas que apresentam um alto rigor e complexidade. Em geral, tal rigor constitui-se como um estranhamento para os estudantes no início de sua graduação. Tal "dureza" emana também por constituir-se numa área em que a especialização, a objetividade, a precisão e a não ambiguidade convivem, harmoniosamente, e estabelecem seus pressupostos teóricos e suas verdades sustentadas por uma ciência normal e por seus paradigmas, conforme salientado por Khun (1987).

Em contraposição, de acordo com Pereira (2016), as "Ciências Moles" são as que contemplam a subjetividade da vida e por isso abrem um leque de possibilidades e não uma verdade absoluta. E, também por isso mesmo, são as que entendem os homens na sua complexidade. "O pensamento complexo não é a chave do mundo, mas o desafio a enfrentar (...) não é o que evita ou suprime o desafio, mas o que o ajuda a relevá-lo e, por vezes, mesmo a ultrapassá-lo" (MORIN, 2003, p. 11). A complexidade é o desafio, não é a resposta (MORIN, 2003, p. 147). Dito de outro modo, a complexidade é a possibilidade, não a verdade.Para Santos (2007, p. 52), 
[...] a especialização do saber da forma que conhecemos hoje tem uma clara demarcação no século XVIII e corresponde a uma série de fenômenos apontados pelos grandes pensadores do início do século XX. Acreditava-se que a crescente divisão do trabalho, da racionalidade, da burocracia e dos processos de individualização eram aspectos oriundos do desenvolvimento, da evolução ou progresso da humanidade.

Nesse contexto, de acordo com nossa experiência, os conteúdos nas "Ciências Duras" ainda têm um alto destaque, em detrimento do equilíbrio conteúdo a ser ensinado e aprendizagem a ser construída e mediada pelo professor e estudantes. Nestas Ciências, o conteúdo é o centro das atenções, com uma ênfase somente neste item, bem como na burocracia avaliativa com provas padronizadas que buscam aferir o que foi aprendido, de forma individualizada, em nosso entendimento, adjetivando as características principais ainda presentes na denominação de "Ciências Duras" relativas às Ciências Exatas.

Contudo, questionamo-nos se deve ser sempre assim, ou seja, o centro estar sempre ocupado pelos conteúdos, com a ausência das vozes que participam do processo, mas de acordo com nossas experiências, têm sido abafadas ou silenciadas gradativamente, em prol da manutenção da objetividade e da solidez dos conhecimentos das Ciências Exatas. Conjecturamos que tal silenciamento empobrece a área e afasta muitos estudantes que não se adaptam a esse modelo estruturado e bem delimitado.

Assim, comprova-se, ao longo dos cursos da área de Ciências Exatas, um silenciamentodos alunos nas salas de aula, com a atenção toda voltada para o professor em aulas expositivas, nas quaiseste profissional apresenta os conteúdosque proverão o futuro licenciando que atuará nas salas de aulas de vários níveis de ensino. Além de ministrar os conteúdos, ficaa cargo do professor decidir sobre o que avaliar, como avaliar e aprovar ou não a partir das escolhas docentes. Tal insulamento pedagógico reserva somente ao professor os espaços de discurso, com poucos diálogos, pouca argumentação discente e um predomínio de decisões no âmbito docente.

O silenciamentoa que nos referimos, se por um lado proporciona aoslicenciandos observareme se concentraremno que lhesé apresentado, pode tornar cada um destes sujeitos inseguros quando necessitam se pronunciar. Ou seja, desenvolvem-se nashabilidades técnicas matemáticas, porém poucos exercitam a argumentação sobre os problemas que permeiam o processo de tornar-seprofessor regente de turmas com uma rica diversidade social e cultural.

$\mathrm{O}$ rigorpresente e praticado na área é uma tradição que se propaga em cursos de ciências exatas, e isso não é distinto na UFJF, qual seja de que externar dúvidas é um sinal de conhecimento falho ou inconsistente, fazendo com que muitos estudantes se sintam desconfortáveis em se expressarem e argumentarem sobre seus raciocínios e saberes. 
Contextualizando para o que ainda ocorre no contexto da UFJF, nos cursos nas Ciências Exatas, os estudantes aprendemmuitos conteúdos científicos. Contudo, pouco espaço sobra para se debater como a ciência se estrutura e que padrões éticos e estéticos permeiam a constituição da área científica e da formação desse profissional que, munido de muito conhecimento científico, vivenciará as mais variadas experiências no contexto de sala deaula.

Uma exceção talvez ocorra quando da frequiência dos licenciandos em disciplinas de conteúdo pedagógico em certos institutos ou faculdades, em que pode haver uma problematização e, dessa forma, o licenciando, se quiser apresentar argumentação sobre o que está sendo problematizado. Contudo isso, em nosso entendimento e de acordo com nossa experiência escolar e na formação de professores é pouco e pode não ocorrer.

Asseveramos que há muitas possibilidades para que o "dessilenciamento" ocorra, além do que propomos nesse relato. Incentivar a escrita e depois a apresentação de seminários, o uso de dinâmicas, o teatro ou performances. Em nosso contexto optamos por utilizar o que denominamos por "filmes pedagógicos", termo que nasceu na pesquisa de Rosa e Kistemann Jr.(2015). Esses filmes, em nosso entendimento, são filmes que podem auxiliar na condução do "dessilenciamento" com a ocorrência de debates e depoimentos acerca das imagens fílmicas exibidas, propiciando ainda atividades de escrita sobre os temas tratados e avaliação da evolução da argumentação discente. Ainda destacamos a oportunidade que os temas tratados podem aproximar os discentes de cenários que ocorrem no cotidiano escolar e que nem sempre a graduação é capaz de prover os futuros professores com certas experiências ou discussões sobre as mesmas.

Destacamos que o Cinemática-Cinema e Debate iniciaram suas açõesno Instituto de Ciências Exatas (ICE-UFJF), mais especificamente no Departamento de Matemática e nas ações de educadores matemáticos, autores desse artigo.

O projetooriginou-se da necessidade de se debater na graduação questões ligadas à prática do magistério e as demandas que foram divulgadas pelo Ministério da Educação (MEC) com relação aos temas de Relações de Gênero, temas Étnico-Raciais, Diversidade e Inclusão.

Esses temas são novos e as Ciências Exatas têm tentando, em nosso contexto e na ação, problematizar esses temas ligando-os ao cotidiano escolar docente e discente. Diante dessa nova demanda, com a criação do projeto com debates sobre esses temas, surgiu o Cinemática e sua proposta de convite ao "dessilenciamento", buscando nas vozes discentes os conhecimentos extracurriculares, os saberes relativos à Matemática Acadêmica, bem como os 
saberes relativos à Matemática da rua que, muitas vezes são abafados pelos conteúdos programáticos problematizados nas Ciências Exatas.

É importante destacar aqui a nossa concepção de saber que compartilhamos com Tardif (2002). Ressalvamos que paraTardif (2002), seria um exagero considerar que tudo é saber, isto é, aceitar que todos os construtos humanos, todas as práticas humanas, toda forma de viver se constituam em saber. Assim, Tardif denomina saber unicamente os pensamentos, as ideias, os juízos, os discursos, os argumentos que obedeçam a certas exigências de racionalidade (TARDIF, 2002, p. 199). Tal racionalidade, entendida como capacidade do indivíduo de justificar o seu discurso para um interlocutor que o questiona sobre a pertinência, a adequação e o valor desse discurso, por meio de razões, de declarações, de procedimentos.

Em outros termos, inspirados em Tardif (2002), em nosso entendimento aquele que sabe "dessilenciar-se", justificando seus argumentos a partir de imagens fílmicas como as exibidas no Cinemática. "Dessilenciar-se" nessa racionalidade também pode ser entendido como ao saber algo, o indivíduo expõe-se, abandonando a zona de conforto do silenciamento.

Nossa escolha pelo cinema para o "dessilenciamento" coaduna-se com as ideias de Coelho e Viana (2013, p.4) quando estas educadoras enfatizam que,

O cinema também está carregado de valores e crenças e visões de mundo dos
diferentes grupos sociais que integram as sociedades complexas, tanto devido
à subjetividade dos produtores da película, quanto à do espectador, que
também carrega seus valores e suas crenças, possibilitando-lhe assim o
conhecimento de outras realidades. Com isso, pode-se criar uma barreira
contra o preconceito, contra as diferenças, por meio de filmes. Sendo assim, o
filme pode auxiliar na abordagem dos temas transversais sugeridos nos
Parâmetros Curriculares Nacionais (BRASIL, 1998).

Recordamos os educadores matemáticos Roberto Ribeiro Baldino e Rômulo Campos Lins, quando estes explanavam em suas práticas pedagógicas que a Matemática aprende-se falando, gesticulando, produzindo enunciações e ensina-se ouvindo, buscando entender em que campo semântico os saberes enunciados se constituíam e são compartilhados (ou não) pelos interlocutores.

\section{Inspirações para nossa Experiência em Pesquisas realizadas com Cinema e Educação}

Inspiramo-nos na pesquisa "Luz, câmera, ação! A contribuição dos filmes para a formação de licenciandos em Matemática", orientada pelo primeiro autor desse artigo, realizada no âmbito doMestrado Profissional em Educação Matemática (UFJF), em 2015, 
pela educadora matemática Luiza Harab da Silva Rosa.

A pesquisa em questão buscoudar voz aoslicenciandos, incitar nos mesmos a vontade de "dessilenciar-se". Ocorreu numa universidade pública no Rio de Janeiro, ao longo da realização de uma disciplina da graduação do curso de Matemática. Como resultado principal da investigação, destacamos que a pesquisa possibilitou discussões sobre temas centrais na formação inicial de um professor, qual seja abordando temas fílmicos como o poder e a responsabilidade do professor na sala, o ethos da prática docente, a inclusão de estudantes com diferentes idades e ritmos de aprendizagem e a violência simbólica presente nos ambientes escolares/acadêmicos que, muitas vezes, não são objetos de discussão na graduação.

A pesquisa de Rosa (2015) gerou um produto educacional que convida os professores, de variados níveis de ensino e contextos sociais e culturais, a utilizar-se de imagens fílmicas, em sala de aula, de modo que o professor possa provocar o "dessilenciamento" discente, educando com e pelo cinema, educando pelo olhar, por meio de cenas que podem promover as discussões e as argumentações.

A partir da pesquisa de Rosa (2015) propomos esse projeto que envolveuCinema e Debate na Matemática e nas Ciências Exatas. Em suma, buscamos além de divulgar a sétima arte, o cinema, com temas referentes ao cotidiano docente, também promover o "dessilenciamento" das vozes e convidar ao debate e ao desenvolvimento do senso crítico nas CiênciasExatas.Embora recente nas Ciências Exatas, com propostas isoladas, na área da Educação já há projetos com uma larga experiência que trabalham imagens fílmicas e discussões sobre o cotidiano do professor e o cotidiano escolar em que este profissional se insere.

Destacamos também os projetos de Adriana Fresquet que buscam promover diálogos, a partir das imagens fílmicas e como o realizado por Rosa e Kistemann Jr. (2015), buscando desenvolver a argumentação dos licenciandos, a partir de cenas que envolvem realidades docentes variadas.

Destacamos também as ações da educadora matemática Romélia Mara Alves Souto que buscou por meio da História da Matemática e do Cinema problematizar temas referentes a essa disciplina das Ciências Exatas e imagens fílmicas. As ações de Souto (2013) buscavam discutir relações didáticas possíveis entre o Cinema e a História da Matemática, crendo que tais relações podem contribuir para a formação de professores de Matemática, constituindo um ambiente favorável a aprendizagem matemática e ao desenvolvimento da criatividade e da argumentação a partir do que é problematizado nos filmes exibidos. 
Por fim, nas pesquisas realizadas por Coelho e Viana (2013), Viana (2009; 2010; 2011) e Viana, Rosa e Orey (2011) podemos constatar a preocupação desses educadores matemáticos que vão ao encontro de nossas preocupações. Nessas pesquisas a preocupação foi responder à seguinte indagação: "De que modo os filmes, como meios de ensino, têm sido utilizados em cursos superiores?”. Como resposta principal à indagação tem-se que, em geral, as grandes maiorias dos educadores matemáticos ainda não utilizam filmes em sala de aula como recurso didático, embora considerem importante seu uso como meio de ensino e reflexão sobre temas pertinentes ao ambiente escolar.

De acordo com Coelho e Viana (2013), para a utilização do cinema como ferramenta educativa, o professor tem de descobrir nos filmes o processo de escolarização e retirar deles reflexões que instiguem o aluno a raciocinar, ser crítico e educar seu olhar, o que constitui-se como a chave da utilização do cinema na sala de aula. A questão desafiadora que se coloca pelas pesquisadoras é desvendarcomo as aulas de Matemática podem ser favorecidas por este recurso imagético. Complementamos tal afirmativa concordando com Viana (2009) quando esta educadora matemática enfatiza que há necessidade de procurar meios pedagógicos para provocar a aprendizagem dos alunos, pois um dos objetivos da educação é encontrar instrumentos apropriados para implementação das novas tecnologias de informação e comunicação, no processo de ensino e de aprendizagem.

Para Alencar (2007) o cinema possibilita o encontro entre pessoas, ampliando o mundo de cada um, mostrando na tela o que é familiar e o que é desconhecido e estimula o aprender.Alencar (2007) ainda enfatiza que o cinema aguça a percepção a torna mais ágil o raciocínio na medida em que, para entendermos o conteúdo de um filme, precisamos concatenar todos os recursos da linguagem fílmica utilizados no desenrolar do espetáculo e que evoluem com rapidez (ALENCAR, 2007, p. 137). As afirmações desse autor coincidem com nossas crenças e podem ser viabilizadas no contexto escolar e acadêmico, conforme nossas investigações comprovaram.

Assim, Educação, Cinema e Arte são temas que podem e devemestar agregados, compondo atividades dinâmicas que proponham a reflexão e propiciem a aquisição de conhecimentos para vários setores do ensino e da aprendizagem. Usar a Arte, em suas várias facetas e manifestações, como artifício para a educação não é nenhuma novidade, é possível encontrarmos trabalhos que relacionem as artes musicais, corporais e imagéticas com a educação, cada uma em separado da outra. 
Nosso mundo é inserido por completo em diversos tipos de artes que vai desde um grafite pela rua até os filmes que escolhemos assistir nos cinemas ou em casa e eles exercem sobre nós diferentes sentimentos e reações principalmente quando abordados junto à educação. Para Fresquet (2013, p.9), “as artes provocam, atravessam, desestabilizam as certezas da educação, perfuram sua opacidade e instauram algo de mistério no seu modo explícito de se apresentar, ao menos, no espaçoescolar”.

Também inspirados nessa fala de Fresquet (2013), Duarte (2002) e Tardif (2002) sobre Cinema e sobre a Formação de Professores que nos sentimos motivadosa promover a desestabilização dos estudantes e professores com relação a seus paradigmas e às suas certezas, sobre como se faz educação e como se ensina ou como se aprende nas Ciências Exatas. Tínhamos, por hipótese,que o Cinema poderiae deveriaauxiliar nos questionamentos sobre a formação de professores, e sobre as metodologias que regem a formação inicial e a formação continuada.

Tal feito ocorre na medida em que as artes fílmicas provoquem, atravessem e desestabilizem o sujeito e este se sinta convidado a argumentar e a defender o seu ponto de vista. Destarte, propiciamos com tal desestabilização a gênese de um sujeito crítico que se utiliza de várias lentes para exercitar seus múltiplos olhares, múltiplas sensações, em contraposição ao que se apresentam nos cursos de Ciências Exatas. Nestes cursos, o positivismo, a unilateralidade de opiniões, a autossuficiência das metodologias de ensinoe os dogmas ainda prescrevem o que é, o que foi e o que será, sem discussões, provocando a esterilização do poder de argumentação do sujeito por meio de seu silenciamento.

Assim, de acordo com Gonzaga (2011), conceitos científicos no ensino de Física, de Química, de Biologia e da Matemática, conquistaram um status quo ao longo da História, e seus discursos por si mesmos por serem reconhecidos prioritariamente como Ciências, tornando-se muitas vezes autossuficientes. São capazes de capturar para si uma espécie prepotência em resolver os problemas humanos por meio do conhecimento científico, predominantemente empirista, que opta por apostas no realista e construtivismo social.

Em consonância com Gonzaga (2011) e em sintonia com nossas ações, Krul e Emmel (2016, p. 282) destaca que,

[...] o Positivismo repercute seus ideais em um modelo de educação tecnicista, que reduz a preocupação à formação escolar técnica, na qual o incentivo ao pensamento crítico é extremamente diminuído ou inexistente, pois cabe ao aluno aceitar os conhecimentos técnicos que advém do conhecimento científico. 


\section{A dinâmica da experiência e como tudo transcorreu...}

Nessa experiência que se constituiu numa iniciação científica, ao longo de 12 meses, objetivou-se:

(i) Promover sessões de cinema com temáticas ligadas ao cotidiano do professor;

(ii) Proporcionar ambientes de debate e argumentação a partir de imagens fílmicas no ambiente universitário com licenciandos das Ciências Exatas;

(iii) Possibilitar o desenvolvimento de múltiplos olhares sobre temas relativos à formação de professores (inicial econtinuada);

(iv) Buscar promover o "dessilenciamento" dos sujeitos e exercitar a argumentação a partir de temáticas oferecidas em filmes de caráterpedagógico;

(v) Convidar os participantes a desenvolver sua autonomia intelectual a partir de debates e argumentações;

(vi) Ampliar o campo de pesquisa que congrega Educação, Cinema e Arte com novas pesquisas e resultados.

As sessões eram sempre organizadas com a presença do coordenador do projeto e a bolsista de iniciação científica selecionada. Antes da ocorrência das sessões fílmicasambos cuidavam da divulgação em murais virtuais e convencionais, (re)assistiam antes os filmes e buscavam trazer para a sessão temas a serem problematizados. Durante a realização da experiência, a dupla orientador-bolsista ainda realizou leituras e aprofundamentos sobre pesquisas envolvendo Educação e uso do Cinema na sala de aula.

Neste projeto utilizamos da abordagem da Pesquisa Qualitativa, de seus paradigmas e instrumentos para investigar a potencialidade de sessões fílmicas, de modo à "dessilenciar" os participantes e convidá-los a se exporem, exercitando um olhar crítico e sua argumentação para seu desenvolvimento enquanto sujeito atuante no meio educacional, em formação inicial ou continuada. Assim, condução de nossa experiência se deu na perspectiva da Metodologia de Pesquisa Qualitativa, e os procedimentos consistiram em caderno de campo, grupo de discussão após a exibição dos filmes com breves entrevistas semiestruturadas e observação participante do orientador do projeto e da bolsista de iniciação científica.

Realizaram sessões fílmicas periódicas para os licenciandos e professores num Instituto de Ciências Exatas, para que, a partir das exibições fílmicas, pudéssemos produzir dados para análise e, conseguinte execução dos objetivos explicitados anteriormente. As sessões eram marcadas a partir do calendário acadêmico, buscando não 
coincidir com períodos de provas que os discentes precisam realizar. Dessa forma, as sessões eram pré-divulgadas em ambientes frequentados pelos docentes e discentes por meio de cartazes virtuais no Facebook e em murais do instituto e portal da universidade. A Figura 1, a seguir, exemplifica como a divulgação era feita:

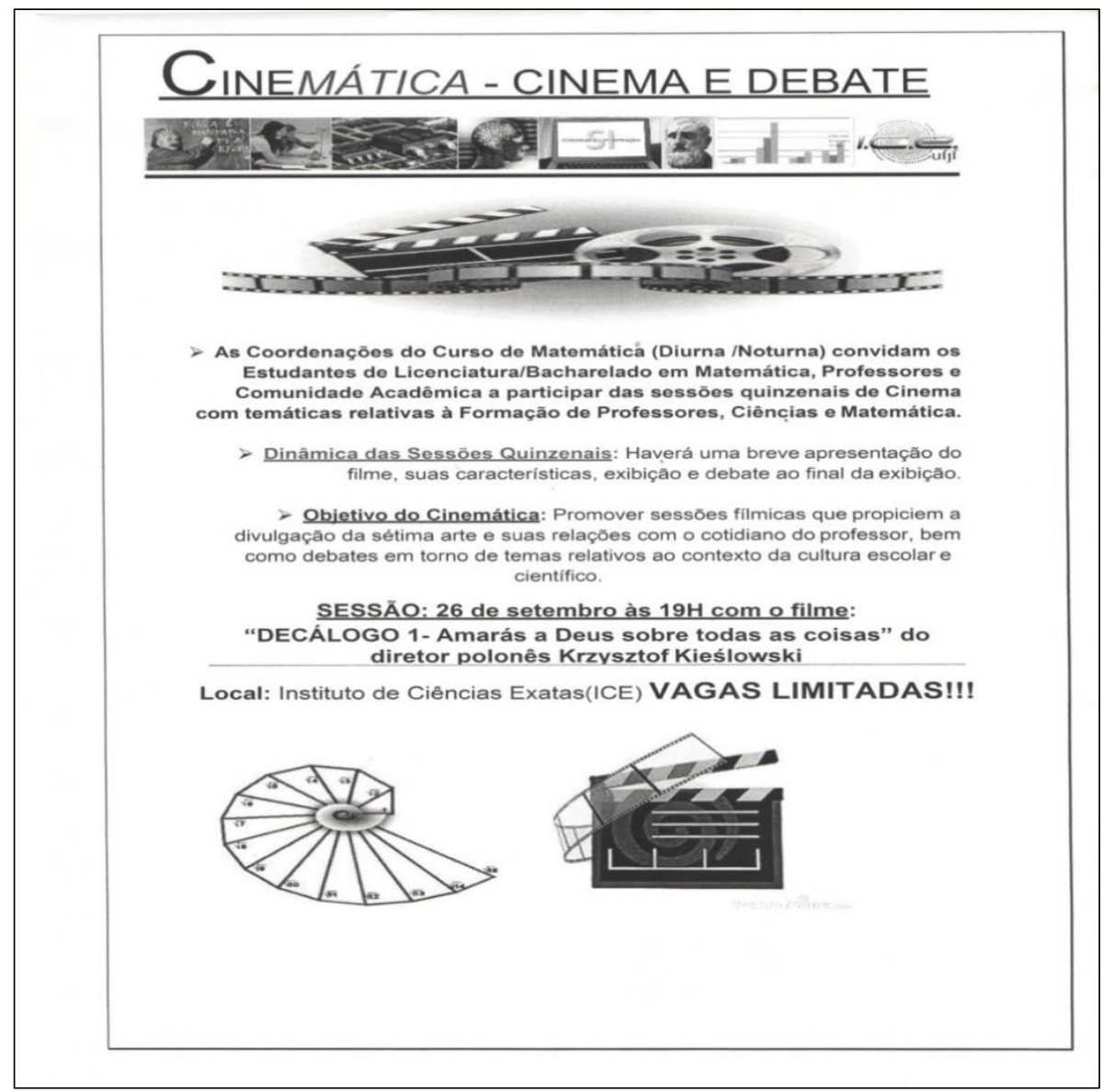

Figura 1: Cartaz de Divulgação.

Fonte: Arquivo dos autores.

A figura 2 a seguir mostra o logotipo criado para o projeto:

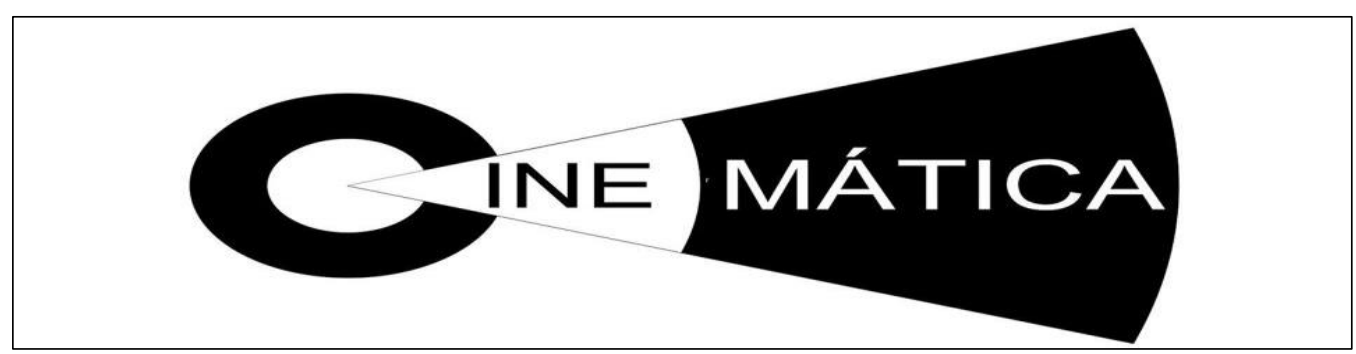

Figura 2: Logotipo

Fonte: Arquivo dos autores

A dinâmica do Cinemática consistia de, ao definido um dia e divulgada a sessão exibir um filme, nacional ou estrangeiro que possibilitasse um debate após a exibição do mesmo. Em geral, os filmes exibidos tinham duração de 90 a 120 minutos, com um breve 
comentário dos organizadores antes da projeção acerca da temática tratada. Após a exibição, havia um espaço de 30 minutos para que os participantes "dessilenciassem" e apresentassem seus argumentos sobre as imagens exibidas.

Os filmes foram escolhidos pelos organizadores do Cinemática, orientador e bolsista do projeto e tinham sempre o mote do professor, da sala de aula, metodologias alternativas de ensino e de aprendizagem e o cotidiano docente e discente. Dessa forma, destacamos três filmes escolhidos para incentivar o "dessilenciamento" discente e que tiveram grande participação:

- “Decálogo 1: Amarás a Deus sobre todas as coisas” (1988) do diretor polonês Krysztof Kieslowski cuja temática central tratava da ideologia da certeza da Ciência em prever com exatidão situações do cotidiano e como podem ser tomadas decisões a partir da Ciência, em geral, inquestionável devido ao rigor de suas metodologias e padrões que asseguram alta confiabilidade. A temática abordada nesse filme reifica a Ciência, em particular a Computação e a Estatística, capazes de dar certezas para assegurar aos indivíduos uma tomada de decisão com grande margem de acerto. $\mathrm{O}$ foco dos debates, após a sessão com a participação dos estudantes e professores presentes, girou em torno dos cuidados que devemos ter ao dar todo o crédito para métodos matemático-computacionais e estatísticos. Em geral, nas Ciências Exatas, exalta-se que o rigor adotado nas metodologias científicas que buscam garantir a fidedignidade dos resultados e garantir o que deve ser feito para a solução de um determinado problema. Contudo, como expõe a película e como foi debatido a exatidão apresentada pelos dados obtidos, de forma rigorosa, não pode ser a última resposta para a tomada de decisões, uma vez que fatores externos, sociais, culturais, religiosos ou climáticos podem e interferem na exatidão apresentada pela frieza dos números.

- “Wiplash - Em busca da perfeição" (2014) trata da tensa relação professor-aluno numa escola de música de excelência abordando o tema do assédio moral. A temática abordada nesse filme possibilitou reflexões sobre o relacionamento professoraluno e os códigos de ética que podem permear a busca por uma excelência no campo da aprendizagem. Uma película que trata também da violência simbólica que permeia o âmbito escolar e as pressões a que são submetidos os alunos na busca da perfeição e da meroticracia.

- Em “Tudo que aprendemos juntos" (2015)tivemos além da exibiçãodo filme, um debate com a participação de um professor de Matemática da rede pública. Isso foi enriquecedor e propiciou a argumentação dos participantes, uma vez que a temática 
abordada por esse filme brasileiro é a atuação de um professor em escolas de periferia com altos índices de violência e abandono por parte do setor educacional e público. A realidade apresentada nas cenas possibilitou a reflexão dos licenciandos presentes, enriquecida pelos depoimentos do professor convidado para o debate que abordou a realidade das escolas de periferia e as práticas docentes em ambientes sitiados pelo tráfico de drogas e ausência do Estado.

Outros filmes foram trabalhados buscando divulgar o cinema e buscando acima de tudo atingir nosso objetivo qual seja de provocar o "dessilenciamento" por meio das imagens fílmicas exibidas com temas relativos ao cotidiano de professores.

Dessa forma, outros filmes como "O clube do imperador" (2002), "A onda" (2015), “A caça" (2012) e "Uma lição de vida (2016) também estiveram em cartaz nas sessões do Cinemática e na pesquisa de Rosa (2015) tratando de temas como a competição na escola, a cola, a ética docente, a liderança docente na manipulação dos estudantes em projetos escolares e o tema da pedofilia no âmbito escolar e da educação e alfabetização de jovens e adultos.

Concordamos com Fresquet (2013, p. 12) quando diz que,

[...] o cinema nos oferece uma janela, pela qual podemos nos assomar ao mundo para ver o que está lá fora, distante no espaço ou no tempo, para ver o que não conseguimos ver com nossos próprios olhos de modo direto. Ao mesmo tempo, essa janela vira espelho e nos permite fazer longas viagens para o interior, tão ou mais distante de nosso conhecimento imediato e possível.

Destacamos, por fim, o potencial qualitativo de tais filmes para o estabelecimento de diálogos sobre temas muitas vezes ignorados nas Ciências Exatas e constituintes de tabus também no âmbito universitário brasileiro.

\section{Depoimentos e resultados da experiência}

As vivências do orientador e da bolsista nessa experiência, buscando investigar em que medida as ações do projeto possibilitariam o "dessilenciamento" e a argumentação dos participantes produziu alguns resultados que nem estava previsto na versão original do projeto cadastrado na Pró-Reitoria de Pesquisa da UFJF.

O projeto ainda tem vigorado sem o vínculo obrigatório de ser uma iniciação científica e passou a compor um espaço na Semana da Matemática do Instituto. Entendemos que o processo de "dessilenciamento" iniciou-se nessas sessões do Cinemática, mas devem continuar em nossas práticas como professores. 
Como alguns professores compareciam às sessões, conjecturamos que estes sujeitos podem também contribuir com esse "dessilenciamento" discente vislumbrando uma sala de aula de Matemática em que a argumentação, o diálogo e a construção de ideias ocorra de uma forma simétrica e democrática. Tais características, descobrindo fazendo o Cinemática fortalecem os laços de afetividade entre o professor e os estudantes, contribuindo para a aprendizagem significativa, uma vez que a voz dos estudantes pode auxiliar significativamente ao professor para que o conhecimento ocorra e seja ampliado de forma autônoma por esses estudantes.Alguns depoimentos revelam a relevância da experiência:

O cinema nos faz vivenciar experiências jamais imaginadas, e supor quais seriam as nossas melhores opções caso estivéssemos no lugar das personagens. Desta forma, experienciar tais situações pode ser mais frutífero caso pudéssemos discutir com nossos colegas de estudo. Então, a sétima arte pode usar o espaço da universidade para suprir o desejo que temos em dividir nossas críticas e apontamentos sobre este ou aquele filme, e ir além das longas horas de estudos que precisamos passar sozinhos. Assim, o espaço Cinemática nos auxilia a criar laços de amizades e ver o mundo compartilhando experiências e aprendendo a conviver com os outros. (Participante E.S.- Professor-UFJF).

O cinema retrata a ficção e realidade. Perceber essas diferenças ou semelhanças com o cotidiano do licenciando gera debates construtivos à medida em que questionamos o personagem e o modo como este interage no contexto. Os diversos filmes nos trouxeram panoramas que além de irem fora da sala de aula, retrataram tema transversais que vivenciamos como licenciandos. Os filmes nos estimularam ainda a falarmos sobre economia, temas de gênero, relação professor-aluno, enfim temas não abordados ou pouco discutidos na graduação em Matemática". (Participante S.C.- Estudante da Matemática- $7^{\circ}$ período).

"No ambiente acadêmico um filme de arte permite o entretenimento do encontro para refletir. Refletir em comunidade sobre a racionalidade, bem como a existencialidade humana. Isso só a arte permite. Como ela também incomoda, não é um simples entretenimento. (Participante A.D.- Estudante da Matemática- $4^{\circ}$ período).

Quando assisto a um filme ou um documentário, ou participo de algum debate na universidade em que ocorreu o Cinemática, imediatamente me reporto a alguma realidade ou toda realidade vivenciada por jovens nas escolas que trabalho através do PIBID Matemática. Considero que por este prisma do conhecimento, como o cinema, consigo perceber como determinados assuntos são vistos socialmente. Um exemplo seria o consumo e como trabalharmos a Matemática para tomar decisões, para consumir de forma consciente. Outro exemplo problematizado no Cinemática foram filmes de pessoas especiais que se transformaram com a percepção adequada de quem o assistiu. Encontros como os do Cinemática 'abrem nossa cabeça e soltam a nossa voz', literalmente. (Participante C.B.Estudante da Ciência da Computação- $6^{\circ}$ período).

Em minha participação como aluno e espectador na primeira versão do projeto Cinemática pude perceber o envolvimento dos alunos, na maioria professores em formação inicial ou continuada, das quais colhi algumas impressões. É importante ressaltar que tais impressões emergem do alto dos meus vinte e dois anos de experiência docente, em Matemática, no contexto da Educação Básica 
e pública. Os encontros referentes ao projeto Cinemática consistem da exibição de filmes e documentários que remetem, direta ou indiretamente, a situações relacionadas à Educação escolar em todas as suas dimensões. Em seguida, os ouvintes são convidados a dialogarem e refletirem sobre as obras que assistiram. Nessas interações, pude perceber a emoção transbordar nas falas dos espectadores que se identificavam ou solidarizavam com personagens dessas obras. Ficou muito claro, para mim, que esse contato com as artes cinematográficas, de certa maneira, "quebrava o gelo" entre os participantes no sentido de encorajá-los a falarem das suas próprias angústias e dilemas, enquanto alunos e/ou professores de Matemática. (Participante N.C.Estudante da Matemática- $2^{\circ}$ período).

Diante desses depoimentos, destacamos como os principais resultados desse projeto:

- Participação da comunidade acadêmica e demais interessados em sessõesfílmicas;

- Desenvolvimento das habilidades argumentativas e do senso crítico dosparticipantes;

- Promoção de espaços de "dessilenciamento" e de promoção de debates democráticos acerca de temaseducacionais;

- Ampliação dos olhares para múltiplos temas apresentados nas sessõesfílmicas;

- Incentivo à criação no ambiente escolar e universitário de espaços de diálogo e convivência que congrega diversas etnias, diversos gêneros e sujeitos culturais em busca do estabelecimento de ambientes dealteridade.

- $\quad$ Apresentação de resultados em eventos científicos da Matemática e da Educação Matemática na UFJF e em outros contextos sociais escolares.

\section{Considerações finais}

O tema desse relato que pode se classificado como um caso buscou explicitar inicialmente uma angústia dos autores no tocante ao silenciamento que ocorre nas Ciências Exatas ao longo da licenciatura. É importante destacar que a aprendizagem ocorre de forma significativa quando certas condições físicas são proporcionadas. Entre elas, destacamos ambientes atrativos e acolhedores. Contudo, na sala de aula, o silêncio dos discentes muitas vezes pode ser interpretado como concentração ou aprendizagem.

O silêncio faz parte de um processo educativo, um sujeito fala, outro sujeito ouve, reflete e argumenta. Porém, em nossa experiência tal sequência nem sempre ocorria 
assim. Ao professor era reservado o uso da palavra e, ocasionalmente, o estudante se pronunciava. Tal constatação nos instigou a promover o "dessilenciamento" nas Ciências Exatas. A forma escolhida foi o uso de cinema ou imagens fílmicas que fossem os disparadores de discussões, promovendo a argumentação espontânea dos professores, mas principalmente dos estudantes que participassem das sessões do Cinemática.

Reiteramos que essa é uma de muitas formas de promover um "dessilenciamento". Temos percebido que trabalhos em grupos bem orientados ou seminários também podem promover o "dessilenciamento". Entretanto, há ainda uma predominância de aulas expositivas que têm seu espaço, mas conservam o professor como aquele que predomina na argumentação, buscando ensinar, sem ter oportunidade, em geral, de averiguar a aprendizagemad hoc. Por exemplo, temos realizado pelo menos duas vezes por semestre, saraus buscando divulgar as vozes e os talentos docentes e discentes presentes nas ciências exatas, como aptidão para ler e escrever poesias, tocar instrumentos musicais ou recitar o que pensam em performances que revelam que devemos nos "dessilenciar", revelar o que pensamos, aprender a ouvir e respeitar o que nos parece diferente e novo.

O "dessilenciamento" diante do que vivenciamos em nossa experiência no Cinemática requer responsabilidade e alteridade sobre o que se fala, sobre quem se fala e para que se fala algo. Não é propor que as pessoas falem por falar, mas façam uso da palavra para expressar o que leram nas imagens e como ao falar podemos entender como o conhecimento se constrói e pode ser avaliado por quem nos ouve.

Assim, dessilenciar-se no contexto da Matemática é ensinar ouvindo o que os estudantes têm para falar, ou seja, ao falarmos revelamos o que sabemos, porque sabemos e como sabemos. Os professores diante das falas dos discentes podem auxiliar na regulação das aprendizagens e entender de onde falam seus estudantes, em que cenário cognitivo ou semântico se encontram os conhecimentos de seus estudantes, ou seja, ao "dessilenciarmos" um conhecimento surge e é compartilhado e o processo pode proporcionar o que buscamos: a aprendizagem. Basta começar sabendo que os desafios são grandes e que as zonas de conforto serão temporárias. Então: "Dessilenciemo-nos"!

Agradecimentos: A realização dessa experiência foi possibilitada graças ao auxílio do CNPq que proveu a bolsista com uma bolsa advinda do Programa Institucional de Bolsas de Iniciação Científica (XXV/PIBIC/CNPq-2016-2017).

A dois educadores matemáticos, Roberto Ribeiro Baldino e Rômulo Campos Lins (in memorian) que, poeticamente, nos ensinaram que saber e sabor podem compor os 
ingredientes mais essenciais da prática educativa, dessilenciadora e renovadora de esperanças, em tempos temerosos e encardidos por práticas fascistas.

\section{Referências}

ALENCAR, S.E.P.O cinema na sala de aula: uma aprendizagem dialógica da disciplina história. n.f. 2007. Dissertação de Mestrado. Faculdade de Educação. Universidade Federal do Ceará. Fortaleza/CE, 2007.

CARRIÈRE. J. A linguagem secreta do cinema. Rio de Janeiro: Editora Nova Fronteira, 2014.

COELHO, R.; VIANA, M. C. V. A utilização de filmes em sala de aula um breve estudo no Instituto de Ciências Exatas e Biológicas da UFOP. Revista da Educação Matemática da UFOP, s. 1., v.1, p.89 - 97, 2013.

DUARTE, R. Cinema \& educação. Belo Horizonte: Autêntica, 2002.

FRESQUET, A. Cinema e educação: Reflexões e experiências com professores e estudantes de educação básica, dentro e fora da escola. Belo Horizonte: Autêntica, 2013.

GONZAGA, A. M. A natureza das afirmações científicas e o cientificismo no ensino de ciências. Revista Areté, Manaus, v. 4, n. 6, p.1-8, jan/jul, 2011.

KRUL, A. J.; EMMEL, R. A influência da ciência do Positivismo Comteano no pensamento educacional brasileiro. Revista da SBEnBio (VI Enebio e VIII Erebio Regional 3), s. 1, n. 9, 2016.

KUHN, T.S. A estrutura das revoluções científicas. São Paulo: Perspectiva, 1987.

MORIN, E. Os sete saberes necessários à educação do futuro. 2. ed. São Paulo: Cortez, 2003.

PEREIRA, P. S. "Ciências Duras" e "Ciências Moles". Revista Pensar Enfermagem, s. 1., v. 20, n. 1, 2016.

ROSA, L.H.S. Luz, Câmera, Giz, Sala de Aula: Ação!: uma investigação sobre a contribuição dos filmes na formação inicial dos professores de Matemática. n.f. 2015. Dissertação de Mestrado Profissional em Educação Matemática. Universidade Federal de Juiz de Fora, Juiz de Fora: [s.n], 2015.

ROSA, L.H.S; KISTEMANN JR., M.A. Investigando a contribuição de filmes para a formação inicial de professores de Matemática. In:SEMINÁRIO DE FORMAÇÃO DE PROFESSORES E II INTERNATIONAL CONFERENCE IN TEACHER EDUCATION, 5, 2015. S.l.

Anais...S.1: UFTM, 2015.

SANTOS, J.V. T.; BAUMGARTEN, M. "Editorial”. Sociologias, v. 8, p. 10-13. SOPER, 2007.

SOUTO, R; M. A. Cinema e História da Matemática. Entrelaços Possíveis. 1. ed. São Paulo: Livraria da Física, 2013.

VIANA, M. C. V. TEIXEIRA, A. F.A História da Matemática vai ao cinema In: SEMINÁRIO NACIONAL DE HISTÓRIA DA MATEMÁTICA, 8. 2009, Belém-PA. Anais... Rio Claro-SP: SBHMat, 2009. 1 cdrom. p. $1-11$. 
VIANA, M. C. V. O Cinema na Sala de Aula e a Formação de Professores de Matemática. Minicurso oferecido aos alunos do Curso de Matemática na UFRRJ. Dia de Atividades Acadêmico-Científico-Culturais. 18 de maio de 2010. Seropédica- RJ.

VIANA, M. C. V. A formação de professores vai ao cinema: 51 roteiros de filmes para serem usados na sala de aula. Ouro Preto: UFOP, 2011. 209 p.

VIANA, M. C. V.; ROSA, M; OREY, D. C. O cinema vai à escola: registrando a diversidade cultural na sala de aula. In: SIMPÓSIO DE FORMAÇÃO E PROFISSÃO DOCENTE, 8. 2011, Mariana-MG. Anais... do VIII SIMPOED. Ouro Preto-MG: UFOP, 2011.

TARDIF, M. Saberes docentes e formação profissional. 4. ed. Petrópolis: Vozes, 2002.

Recebido em: 11 de maio de 2018.

Aceito em: 08 de agosto de 2018. 